\title{
Resistant Evaluation of Kiwifruit Rootstocks to Root Zone Hypoxia Stress
}

\author{
Yinfa $\mathrm{Mi}^{{ }^{*}}$, Xiaowei $\mathrm{Ma}^{2}$, Shuangchen $\mathrm{Chen}^{1}$ \\ ${ }^{1}$ Forestry College of Henan University of Science and Technology, Luoyang, China; ${ }^{2}$ Subtropical Crops Research Institute, Chinese \\ Academy of Tropical Agricultural Sciences, Zhanjiang, China. \\ Email: *jimiapple@126.com
}

Received March $6^{\text {th }}, 2013$; revised April $6^{\text {th }}, 2013$; accepted April 14 ${ }^{\text {th }}, 2013$

Copyright (C) 2013 Yinfa Mi et al. This is an open access article distributed under the Creative Commons Attribution License, which permits unrestricted use, distribution, and reproduction in any medium, provided the original work is properly cited.

\begin{abstract}
In this thesis, 10 species of kiwifruit rootstocks were treated with hydroponics hypoxia to study their root zone hypoxia tolerance. The results were as follows: growth of all kiwifruit seedlings was inhibited. The max length of new root, plant height, plant biomass, root activity, relative growth rate of leaves, and content of chlorophyll in leaves under root zone hypoxia stress obviously declined comparing with control. MDA content, relative conductance in the leaves and roots all increased in 10 kinds of kiwifruit seedlings. The sensitivities of 10 kinds' kiwifruit seedlings to hypoxia stress were obviously different. With the method of subordinate function and cluster analysis, the adversity resistance coefficient of 10 kinds' kiwifruit seedlings, were comprehensively evaluated in order to appraise their hypoxia-tolerance abilities. According to the results, "Hayward", "Qinmei", "Jinxiang", "Kuoye", "Huayou" kiwifruit seedlings held higher tolerance to root zone hypoxia stress, while "Hongyang" kiwifruit seedlings were sensitive to root zone hypoxia stress. The others, including "Xixuan", "Maohua", "Jinhua", "Shanli" kiwifruit seedlings kept moderate resistant intensity to root zone hypoxia stress. The kiwifruit seedlings' resistance order from strong to weak was: "Hayward" > "Qinmei" > "Jinxiang" > "Kuoye" > "Huayou" > "Xixuan" > "Maohua" > "Jinhua" > "Shanli" > "Hongyang".
\end{abstract}

Keywords: Kiwifruit Rootstock; Root Zone Hypoxia Stress; Resistant Evaluation

\section{Introduction}

Molecular oxygen is the terminal electron acceptor in the mitochondrial electron transport chain and is also the prerequisite conditions that were required by higher plants during their growth and development. However, anoxia is a common environmental challenge which plants have to face throughout their life. Winter ice encasement, seed imbibitions, floods, soil compaction and excess of rainfall are examples of nature conditions leading to root hypoxia or anoxia. Low oxygen concentration is also a normal natural environmental stress to plants $[1,2]$. For example, in wetland, the oxygen concentration around the root tissue is nearly zero [3-5]. Plants' survival, growth, development are drastically effected by root zone hypoxia [6,7]. Climate change models also increased the risks of waterlogging root hypoxia $[8,9]$. Hypoxia environment can reduce the redox potential of soil, accumulate the reducing materials, damage the plant root plastosome and protein structure,

"Corresponding author. reduce the cell energy charge and make cytoplasmic acidosis, all of which can restrain the plant growth and lead to death. Under waterlogging stress, the treated plants' height, length and width of leaves, number of green leaves, stem width, root, shoot, and leaf area per plant decreased significantly as well as total dry weight [10]. The reduction in yield potential that is caused by root zone hypoxia stress may be more serious than by other stress, such as, drought [11].

Under root zone hypoxia stress, roots and shoots of the plant are inhibited because of the inordinate physiologic processes, such as chlorophyll biosynthesis, reactive oxygen species (ROS) metabolism, and anaerobic metabolism [12-16]. Numerous studies have shown that hypoxia stress triggers can produce ROS and induce oxidative stress in plants $[17,18]$. At stage of winter rape seedling, waterlogging significantly decreased leaf chlorophyll content and leaf photosynthetic rate, but accumulated leaf malondialdehyde [10]. Root zone hypoxia stress has also been found to injure plants by a rapid reduction in the rate of photosynthesis and stomatal con- 
ductance $[19,20]$.

Moog and Janiesch [21] reported that oxygen deficiency affected production of root biomass in three Carex species from varying hydrological habitats. The degree of stress in root zone hypoxia is associated with growth stage, growth conditions, and genotypes [22-24]. For example, plants are very susceptible to waterlogging at the 6th leaf stage, because the growing point is below the soil surface at that time [25]. Different genotypes plants have different resistance abilities to the root zone hypoxia stress. For example, root zone hypoxia stress inhibited growth of Malus species seedlings, and there were significant differences in intensity among genotypes [26]. The transient waterlogging reduced the seed yield by $54 \%$ in the kabuli cultivar Almaz of chickpea, but by $44 \%$ in the desi cultivar Rupali and root length and root dry matter were higher in the kabuli cultivar Almaz than in the desi cultivar Rupali after waterlogging [27]. Among 30 cross-combinations, the cultivars of Brassica napus L. Zhongshuang 9 and P79 had higher tolerance potential to waterlogging stress. So, combining ability and genetic effects of relative vigor index could be used to identify the plant waterlogging tolerance in breeding program [28].

The kiwifruit (Actinidia deliciosa), native to the Yangtze Valley of China, is a large, woody, deciduous vine. Now it is abroadly planted as a burgeoning commercial planting fruit tree around the world because of the abundant nutrient value. But kiwifruit rootstocks are quite sensitive to waterflooding or excess of rainfall, which can easily produce root zone hypoxia stress and reducing conditions, and these stresses can damage the plants metabolism. So hypoxia stress is incidental to the kiwifruit plants during growing season.

In this thesis, 10 kinds of kiwifruit rootstocks were treated with hydroponics hypoxia to study their root zone hypoxia tolerance. The physiology and biochemical mechanism of hypoxia stress to the rootstocks were discussed, all the above is to provide the theoretic base and technical guideline for the cultivation and soil management.

\section{Materials and Experimental Design}

\subsection{Materials and Methods}

Experiments were conducted at Forestry College of Henan University of Science and Technology, China. Test for kiwifruit materials, which originated from different climate regions in China, were listed in the table (Table 1). Selected plump seeds, dried and stored with a sand bag. Then seeds were stratified in an earthen jar filled with wet sand that was put outside door under the winter natural low temperature conditions from January 9 to March 9, 2010. In March the following year, after germination, seeds were sowed with nutrition matrix in 10 $\mathrm{cm} \times 10 \mathrm{~cm}$ nutritional bowls covered with black plastic sheet to provide darkness and heat preservation. Before sowing, the nutrition matrix was disinfected with 200 times of $40 \%$ formalin solution for 4 days so as to kill the pathogen and eggs in the matrix. Breeding period, nutritional bowls were sprayed with $1 / 2$ concentration of hoagland nutrient solution. When the seedlings reached 6 leaves, they were transferred to $10 \mathrm{~L}$ plastic pots full of hoagland nutrient solution, forty seedlings per pot. The $\mathrm{pH}$ was maintained close to 6.5 by adding diluted $\mathrm{H}_{2} \mathrm{SO}_{4}$ or $\mathrm{KOH}$. After 4-day pre-culture, the plants were treated with root zone hypoxia stress.

The experiments seedlings were subject to hypoxia by flushing nutrient solution with $\mathrm{N}_{2}$ gas for 11 days. The nutrient solution of control plants was continuously

Table 1. Origins of test materials.

\begin{tabular}{|c|c|c|c|}
\hline Code & Chinese name & Species and cultivars & Origin $[30]$ \\
\hline 1 & Shanli & A. rufa & Japan \\
\hline 2 & Maohua & A. eriantha var. & Guizhou, Hunan, Jiangxi, Fujian, Guangdong, Guangxi \\
\hline 3 & Xixuan & A. chinensis var. & Shaanxi, Henan, Anhui, Jiangsu, Zhejiang, Hubei, Hunan, \\
\hline 4 & Hongyang & A. chinensis var. & Jiangxi, Guangdong, Guangxi, Fujian \\
\hline 5 & Kuoye & A. latifolia var. & $\begin{array}{l}\text { Anhui, Zhejiang, Jiangxi, Fujian, Hunan, Sichuan, Yunnan, } \\
\text { Guangxi, Hubei, Guangdong, Taiwan }\end{array}$ \\
\hline 6 & Qinmei & A. deliciosa & \\
\hline 7 & Hayward & A. deliciosa & $\begin{array}{c}\text { Gansu, Shaanxi, Henan, Hubei, Huban, Sichuan, } \\
\text { Yunnan, Guizhou, Guangxi }\end{array}$ \\
\hline 8 & Jinxiang & A. deliciosa & \\
\hline 9 & Jinhua & A. chrysantha & Guangxi, Guangdong, Hunan \\
\hline 10 & Huayou & A. deliciosa $\times$ A. chinensis & Shaanxi \\
\hline
\end{tabular}


flushed with air with an air pump. Oxygen concentration in the vessels was monitored with an oxygen meter (Dissolved Oxygen FC680, East China University of Science and Technology). Dissolved oxygen concentration was about 8.0 - $8.5 \mathrm{mg} \cdot \mathrm{L}^{-1}$ (control) at a normal level and about 0.9 - $1.1 \mathrm{mg} \cdot \mathrm{L}^{-1}$ (hypoxia stress) at a low level. After hypoxia stress treatment, top leaves and roots were randomly sampled so as to analysis each index. Each kind of kiwifruit was treated for 50 seedlings and each index was repeated at least 3 times in order to ensure the accuracy of the experiment.

\subsection{Statistics of the Kiwifruit Seedling Mortality Rate and Growth Measurements}

At the end of treatment, the mortality rate of seedlings was statisticed. After treatment, plant height and max length of new root were measured by a ruler. After water sucked up with absorbent paper, seedlings were put into a drying oven at $105^{\circ} \mathrm{C}$ for 15 min fixation, then dried at $75^{\circ} \mathrm{C}$ for $72 \mathrm{~h}$ to constant weight, used for weighing.

\subsection{Assay of RMP; Root Oxidizability (RO), Chlorophyll Determination; and MDA Content}

RMP was measured according to the method described by Dionisio-Sese and Tobita [29]. RMP was calculated with the formula: $\mathrm{RMP}=\mathrm{L}_{1} / \mathrm{L}_{2} \times 100$. RO was determined with the method of red triphenyl formazan formed through TTC reduction assay [31]. Chlorophyll was determined referring to Wintermans and Demots [32]. Malondialdehyde (MDA) content was measured by the method of Heath and Packer [33].

\subsection{Data Analysis}

Data were analyzed with Excel, SPSS V13.0 software.

\subsection{Membership Function Evaluation Method}

Selecting several representative growth and physiological indexes, then using subordinate function value method to evaluate the root zone hypoxia resistance of kiwifruit seedlings [34]. All kiwifruit seedlings' membership function average values were compared and made comprehensive evaluations to determine their root zone hypoxia tolerance in sequence. The formula was as follows:

$$
\begin{aligned}
& \text { A: } U_{i j}=\frac{X_{i j}-X_{j \min }}{X_{j \max }-X_{j \min }} ; B: U_{i j}=1-\frac{X_{i j}-X_{j \min }}{X_{j \max }-X_{j \min }} ; \\
& C: \bar{U}=\frac{1}{n} \sum_{j=1}^{n} X_{i j}
\end{aligned}
$$

(Type: $U_{\mathrm{ij}}$ represents $\mathrm{i}$ type $\mathrm{j}$ indexes of anti hypoxia subordinate function values; $\mathrm{X}_{\mathrm{ij}}$ represents $\mathrm{i}$ type $\mathrm{j}$ index; $\mathrm{X}_{\mathrm{jmin}}$ represents all kinds $\mathrm{j}$ indexes of minimum value;
$\mathrm{X}_{\mathrm{jmax}}$ represents all types of $\mathrm{j}$ index maximum; $\mathrm{i}$ represents a variety; $\mathrm{j}$ represents some index; $\bar{U}_{i}$ represents mean value of $i$ kinds of anti hypoxia membership function, $\mathrm{n}$ as the index number)

Calculation of test indexes: positively correlated with anti hypoxia, by A formula above; negative correlation, by $\mathrm{B}$ formula above.

\subsection{Cluster Analysis and Root Hypoxia Resistance Grading Evaluation}

Cluster analysis was conducted by method of SPSS software's euclidean distance. Euclidean's distance tests were used to determine average linkage clustering. Material resistance grades were determined according to the results of cluster analyses. Resistance classifications were determined according to membership function index of average value.

\section{Results}

\subsection{Seedling Mortality Statistics and Relative Growth Rate Statistics of Leaves}

Under root zone hypoxia stress, most of "Hongyang" and "Shanli" kiwifruit seedlings wilted apparently and death phenomenon happened at the end of treatment. Mortality rate of them could reach $63.33 \%$. However, mortality rate of "Hayward" and "Qinmei" kiwifruit seedlings only reached 13.33\%, 20\%, respectively (Figure 1(a)). Compared with the other kinds of kiwifruit seedlings, "Hayward" and "Qinmei" kiwifruit showed much stronger resistance.

Under root zone hypoxia stress, length and width growing of each kiwifruit seedlings' leaf was significantly inhibited (Figure 1(b)). But the growth speed of leaf differed with different species of kiwi fruit. The inhibition degree of "Kuoye", "Hayward", "Qinmei" kiwifruit seedlings' leaf length and width growth rate were lower than $20 \%$, while, that of "Jinhua" was more than $50 \%$, much more serious than the above.

\subsection{Dry Weight Statistics of Whole Plant, New Roots Max Length and Plant Height Statistics}

The whole plant dry weight of kiwifruit seedling was also significantly inhibited by root zone hypoxia stress (Figure 1(c)). Compared with the control, the whole plant dry weight of "Hongyang" and "Shanli" kiwifruit seedling reduced at the range of $40 \%$. However, "Kuoye", "Qinmei", "Hayward", "Jinxiang" kiwifruit seedling whole plant dry weight decreased below 20\%. Results were similar to the Brassica [35]. The whole plant dry weight reduction between the 10 kinds of kiwifruit seedlings had significant difference. And the inhibition from 


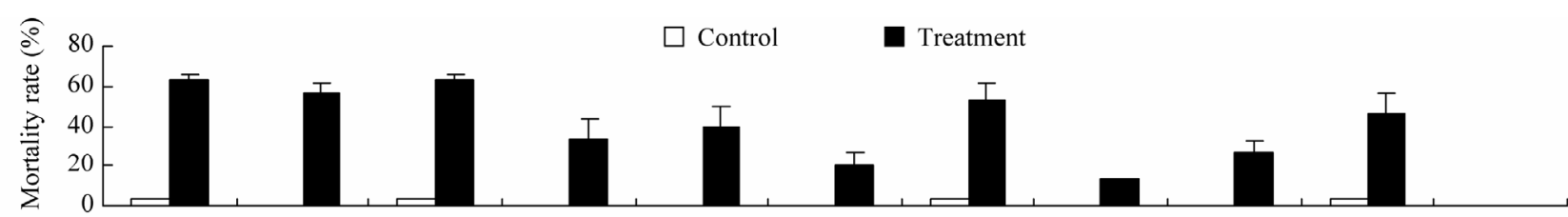

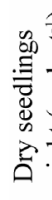

(a)

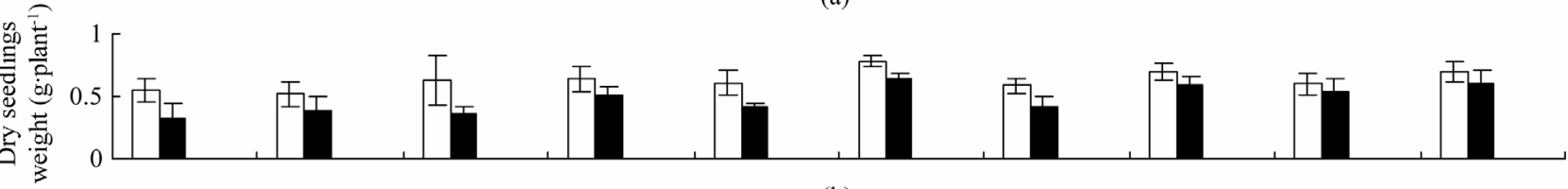

(b)

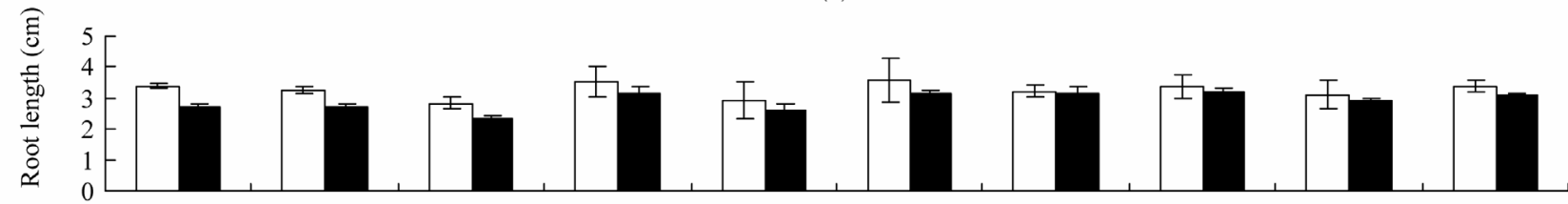

(c)

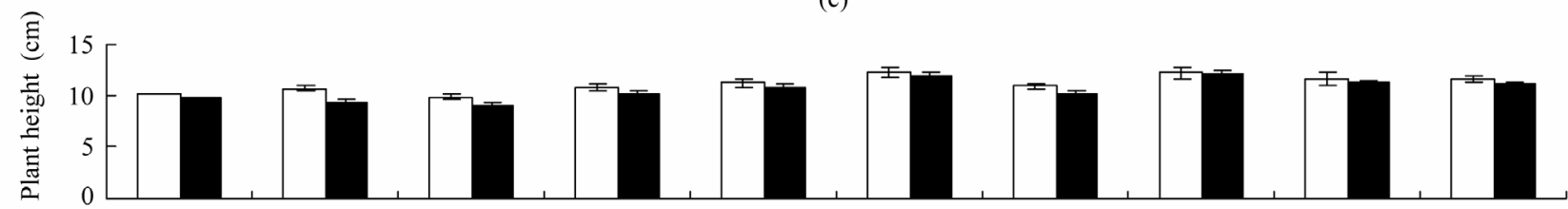

(d)

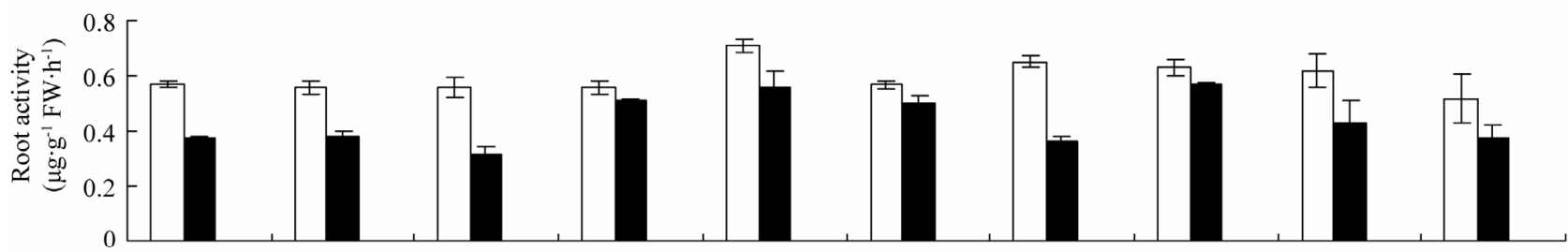

(e)

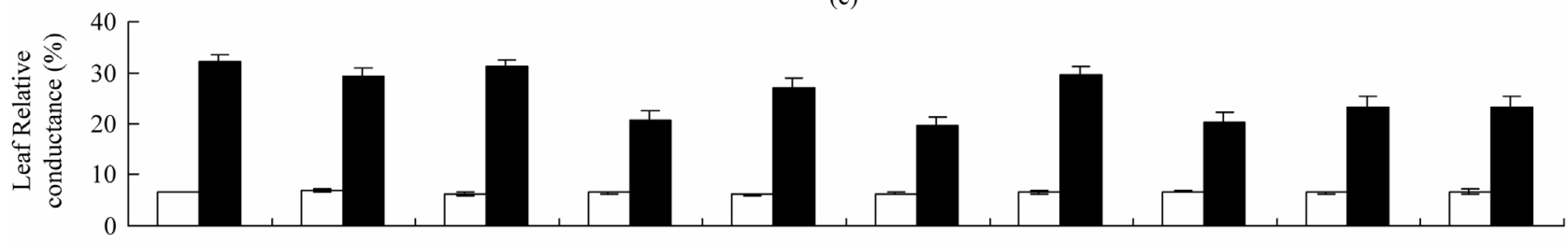

(f)
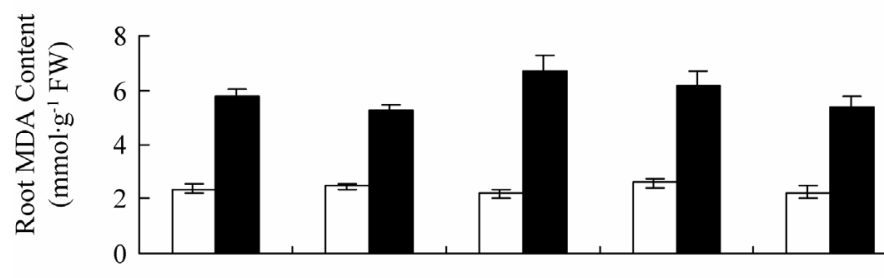

苟
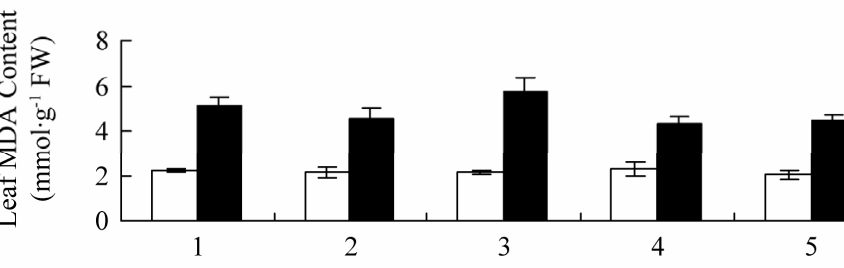

(g)

Figure 1. Effect of root zone hypoxia stress on kiwifruit seedlings. (a) Mortality rate; (b) Dry weight; (c) New root max length; (d) Plant height; (e) Root activity; (f) Leaf relative conductance; (g) Root MDA content; (h) Leaf MDA content. 
the root zone hypoxia stress to the growth of stronger resistant kiwifruit seedlings was in a small extent. Nevertheless, the inhibition of the weaker was in a much extent. So, resistant abilities to the hypoxia stress existed genotype differences among these 10 kinds of kiwifruit seedlings.

Suffered from root zone hypoxia stress, the kiwi fruit seedlings roots and height growth were inhibited in different degrees (Figure 1(d)). New root max length inhibition degrees of "Shanli", "Hongyang", "Maohua" kiwifruit seedling were significant, while those of "Huayou", "Jinxiang", "Hayward", "Jinhua" kiwifruit seedling was not significant. The most serious inhibition of height growth was "Maohua" kiwifruit, and the lightest was "Hayward" kiwifruit.

\subsection{Root Activity, Relative Conductance, MDA Content Statistics and Chlorophyll Contents Statistics in Leaves}

Root activity was a comprehensive index, which reflected root absorbing capacity. The experimental results showed that kiwifruit seedlings' root activity was inhibited by root zone hypoxia stress (Figure 1(e)). Especially, root activity of "Hongyang" and "Jinhua" kiwifruit seedling reduced $44.64 \%, 44.62 \%$ respectively. And "Qinmei", "Hayward", "Kuoye" reduced only $12.3 \%$, 9.5\%, $8.9 \%$, respectively. From above, after treatment, roots of "Hongyang" and "Jinhua" kiwifruit seedling had already lost their activity and the absorbing functions were influenced significantly, while the inhibitions of "Qinmei", "Hayward", "Kuoye" kiwifruit seedling root activity were much smaller.

Under stress, excessive ROS in plants body could cause the membrane lipid peroxidation, increase the permeability of cell membrane, thereby destroy the cell membrane structure and function, which disturbed the plant membrane system. While MDA was the product of plant cell membrane lipid peroxidation, whose content could reflect the cells extent of injury under stress. Compared with control, leaf membrane permeability and MDA content of kiwifruit seedling increased under root zone hypoxia stress (Figure 1(f)). The increase of leaf membrane permeability, MDA content both in leaf and root were all greatest in "Hongyang" kiwifruit seedling, which increased by $405 \%, 172 \%, 206 \%$, respectively. The least increase of leaf membrane permeability, MDA content both in leaf and root were in "Hayward", "Jinxiang", "Huayou" kiwifruit seedling.

Under root zone hypoxia stress, chlorophyll a, chlorophyll $\mathrm{b}$, chlorophyll, chlorophyll $\mathrm{a} / \mathrm{b}$ and carotenoid content of kiwifruit seedlings were destructed and reduced (Table 2). But their decreased level varied with different kiwifruit species. Compared with control, total chloro- phyll content decreased greatly in leaves of "Jinhua", "Hongyang", "Maohua", "Kuoye", "Xixuan" kiwifruit seedling. While total chlorophyll reduction amplitude were smaller in "Jinxiang", "Qinmei", "Hayward" kiwifruit seedling. It was thus clear that, under the same condition of root zone hypoxia stress, "Jinxiang", "Qinmei", and "Hayward" kiwifruit seedling could still keep much higher photosynthetic performance. Chlorophyll a/b decreased slightly but still had significant differences among the 10 kinds of kiwifruit seedling. Under root zone hypoxia stress, carotenoid content also reduced obviously, which decreased at the range of $30 \%-40 \%$ in "Maohua", "Hongyang", "Jinhua" kiwifruit seedlings. And that of "Kuoye", "Xixuan", "Shanli", "Huayou" was about $20 \%$. The carotenoid content reduced by only $10 \%$ in "Qinmei" and "Hayward" kiwifruit seedling.

\subsection{Comprehensive Evaluation about Root Zone Hypoxia Tolerance of Different Kiwifruit Seedlings}

In this study, the resistance capabilities to root zone hypoxia stress were evaluated among the 10 kinds of kiwifruit seedlings. Analysis result showed: the resistance order from strong to weak was: "Hayward" > "Qinmei" > "Jinxiang" > "Kuoye" > "Huayou" > "Xixuan" > "Maohua" > "Jinhua" > "Shanli" > "Hongyang" (Table 3).

On the basis of index membership function value, 10 kinds of kiwifruit seedlings were evaluated with cluster analysis method (Figure 2). The cluster results could be divided into three categories. "Hayward", "Qinmei", "Jinxiang", "Kuoye" and "Huayou" kiwifruit could be clustered into one class. "Maohua", "Xixuan", "Jinhua", and "Shanli" kiwifruit could be clustered into another class. "Hongyang" kiwifruit could be clustered into other class. Therefore, combining the index comprehensive evaluation membership function sequence and the results of cluster analysis, the 10 kinds of materials resistance ability to root zone hypoxia stress could be determined to

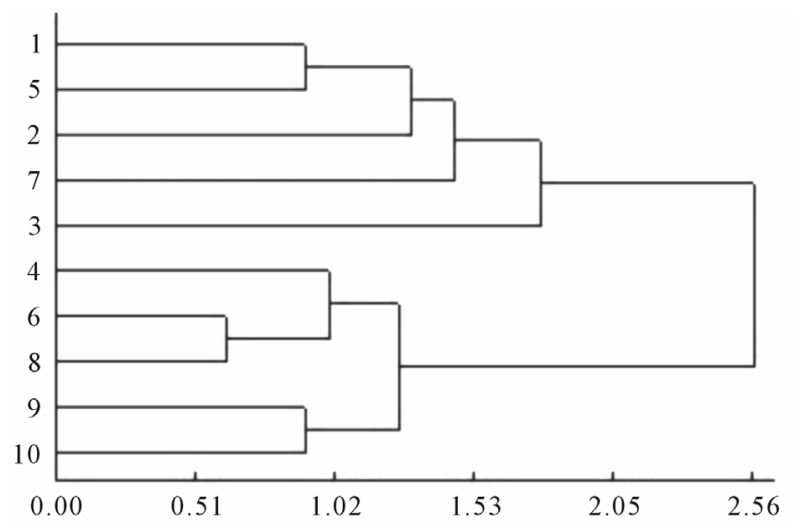

Figure 2. Cluster analysis for root zone hypoxia tolerance of different kiwifruit seedlings (Euclidean's distance). 
Table 2. Effect of hypoxia stress on chlorophyll contents in leaves of $\mathbf{1 0}$ kinds of kiwifruit seedlings.

(a)

\begin{tabular}{|c|c|c|c|c|c|c|c|c|c|}
\hline \multirow{2}{*}{ Material } & \multicolumn{3}{|c|}{ Chlorophyll a $\left(\mathrm{mg} \cdot \mathrm{g}^{-1} \mathrm{FW}\right)$} & \multicolumn{3}{|c|}{ Chlorophyll b (mg.g $\left.{ }^{-1} \mathrm{FW}\right)$} & \multicolumn{3}{|c|}{ Chlorophyll (mg $\left.\cdot \mathrm{g}^{-1} \mathrm{FW}\right)$} \\
\hline & (CK) & (Hy) & Reduce (\%) & $(\mathrm{CK})$ & (Hy) & Reduce (\%) & (CK) & (Hy) & Reduce (\%) \\
\hline 1 & $1.646^{\mathrm{d}}$ & $1.197^{\mathrm{f}}$ & $27.29^{\mathrm{f}}$ & $1.037^{\mathrm{g}}$ & $0.803^{\mathrm{e}}$ & $22.56^{\mathrm{g}}$ & $2.683^{h}$ & $1.999^{\mathrm{f}}$ & $25.53^{\mathrm{f}}$ \\
\hline 2 & $1.768^{\mathrm{b}}$ & $1.103^{\mathrm{g}}$ & $37.62^{b}$ & $1.096^{\mathrm{f}}$ & $0.754^{\mathrm{f}}$ & $31.21^{\mathrm{c}}$ & $2.864^{\mathrm{e}}$ & $1.857^{\mathrm{g}}$ & $35.23^{\mathrm{c}}$ \\
\hline 3 & $1.721^{\mathrm{c}}$ & $1.097^{\mathrm{g}}$ & $36.26^{\mathrm{c}}$ & $0.903^{\mathrm{h}}$ & $0.585^{\mathrm{h}}$ & $35.24^{\mathrm{b}}$ & $2.624^{\mathrm{i}}$ & $1.682^{\mathrm{h}}$ & $35.90^{\mathrm{b}}$ \\
\hline 4 & $1.736^{\mathrm{bc}}$ & $1.195^{\mathrm{f}}$ & $31.17^{\mathrm{d}}$ & $1.173^{\mathrm{c}}$ & $0.861^{\mathrm{d}}$ & $26.61^{\mathrm{e}}$ & $2.909^{\mathrm{c}}$ & $2.056^{\mathrm{ef}}$ & $29.30^{d}$ \\
\hline 5 & $1.765^{\mathrm{b}}$ & $1.236^{\mathrm{e}}$ & $29.95^{\mathrm{e}}$ & $1.133^{\mathrm{d}}$ & $0.872^{\mathrm{d}}$ & $23.05^{\mathrm{f}}$ & $2.898^{\mathrm{cd}}$ & $2.108^{\mathrm{e}}$ & $27.32^{\mathrm{e}}$ \\
\hline 6 & $1.805^{\mathrm{a}}$ & $1.678^{\mathrm{a}}$ & $7.05^{\mathrm{j}}$ & $1.252^{\mathrm{a}}$ & $1.189^{\mathrm{a}}$ & $5.03^{\mathrm{j}}$ & $3.057^{\mathrm{a}}$ & $2.867^{\mathrm{a}}$ & $6.21^{\mathrm{i}}$ \\
\hline 7 & $1.598^{\mathrm{e}}$ & $0.902^{\mathrm{h}}$ & $43.55^{\mathrm{a}}$ & $1.119^{\mathrm{e}}$ & $0.692^{\mathrm{g}}$ & $38.16^{\mathrm{a}}$ & $2.717^{\mathrm{g}}$ & $1.594^{\mathrm{i}}$ & $41.35^{\mathrm{a}}$ \\
\hline 8 & $1.756^{\mathrm{b}}$ & $1.573^{\mathrm{b}}$ & $10.42^{\mathrm{h}}$ & $1.223^{\mathrm{b}}$ & $1.137^{\mathrm{b}}$ & $10.3^{\mathrm{i}}$ & $2.979^{b}$ & $2.710^{\mathrm{b}}$ & $9.02^{\mathrm{h}}$ \\
\hline 9 & $1.657^{\mathrm{d}}$ & $1.509^{\mathrm{c}}$ & $8.93^{\mathrm{i}}$ & $1.119^{\mathrm{e}}$ & $1.114^{\mathrm{b}}$ & $14.2^{\mathrm{h}}$ & $2.776^{\mathrm{f}}$ & $2.623^{\mathrm{c}}$ & $5.52^{\mathrm{j}}$ \\
\hline 10 & $1.713^{\mathrm{c}}$ & $1.288^{\mathrm{d}}$ & $24.81^{\mathrm{g}}$ & $1.173^{\mathrm{c}}$ & $0.938^{\mathrm{c}}$ & $26.85^{\mathrm{d}}$ & $2.886^{\mathrm{d}}$ & $2.226^{\mathrm{d}}$ & $22.93^{\mathrm{g}}$ \\
\hline
\end{tabular}

(b)

\begin{tabular}{|c|c|c|c|c|c|c|}
\hline \multirow{2}{*}{ Material } & \multicolumn{3}{|c|}{ Chlorophyll a/b } & \multicolumn{3}{|c|}{ Carotenoid pigment $\left(\mathrm{mg} \cdot \mathrm{g}^{-1} \mathrm{FW}\right)$} \\
\hline & $(\mathrm{CK})$ & (Hy) & Reduce (\%) & $(\mathrm{CK})$ & (Hy) & Reduce $(\%)$ \\
\hline 1 & $1.587^{\mathrm{bc}}$ & $1.490^{\mathrm{b}}$ & $6.11^{\mathrm{ef}}$ & $0.87^{\mathrm{ab}}$ & $0.69^{\mathrm{ab}}$ & $20.66^{\mathrm{e}}$ \\
\hline 2 & $1.613^{\mathrm{b}}$ & $1.463^{\mathrm{bc}}$ & $9.32^{\mathrm{a}}$ & $0.83^{\mathrm{abc}}$ & $0.55^{\mathrm{cd}}$ & $33.85^{\mathrm{c}}$ \\
\hline 3 & $1.906^{\mathrm{a}}$ & $1.876^{\mathrm{a}}$ & $1.58^{\mathrm{i}}$ & $0.72^{\mathrm{c}}$ & $0.46^{\mathrm{d}}$ & $36.43^{\mathrm{b}}$ \\
\hline 4 & $1.480^{\mathrm{d}}$ & $1.388^{\mathrm{cd}}$ & $6.21^{\mathrm{e}}$ & $0.74^{\mathrm{bc}}$ & $0.54^{\mathrm{cd}}$ & $27.17^{\mathrm{d}}$ \\
\hline 5 & $1.558^{\mathrm{c}}$ & $1.418^{\mathrm{bcd}}$ & $8.97^{\mathrm{b}}$ & $0.82^{\mathrm{abc}}$ & $0.66^{\mathrm{bc}}$ & $19.04^{\mathrm{g}}$ \\
\hline 6 & $1.442^{\mathrm{e}}$ & $1.411^{\mathrm{bcd}}$ & $2.13^{\mathrm{h}}$ & $0.90^{\mathrm{a}}$ & $0.80^{\mathrm{a}}$ & $10.38^{\mathrm{j}}$ \\
\hline 7 & $1.427^{\mathrm{e}}$ & $1.303^{\mathrm{e}}$ & $8.72^{\mathrm{c}}$ & $0.80^{\mathrm{abc}}$ & $0.45^{\mathrm{d}}$ & $43.67^{\mathrm{a}}$ \\
\hline 8 & $1.436^{\mathrm{e}}$ & $1.383^{\mathrm{cd}}$ & $3.65^{\mathrm{g}}$ & $0.73^{\mathrm{c}}$ & $0.63^{\mathrm{bc}}$ & $13.73^{\mathrm{h}}$ \\
\hline 9 & $1.481^{\mathrm{e}}$ & $1.355^{\mathrm{de}}$ & $8.52^{\mathrm{d}}$ & $0.78^{\mathrm{bc}}$ & $0.69^{\mathrm{ab}}$ & $11.28^{\mathrm{i}}$ \\
\hline 10 & $1.460^{\text {de }}$ & $1.373^{\mathrm{de}}$ & $5.98^{\mathrm{f}}$ & $0.81^{\mathrm{abc}}$ & $0.64^{\mathrm{bc}}$ & $20.22^{\mathrm{f}}$ \\
\hline
\end{tabular}

Data with different letters in the same column indicate a significant difference at $\mathrm{p}<0.05$ by LSD test.

three levels. Level one was hypoxia tolerance kiwifruit ("Hayward", "Qinmei”, "Jinxiang", "Kuoye" and "Huayou" kiwifruit). Level two was the medium of hypoxia tolerance kiwifruit ("Maohua", "Xixuan", "Jinhua", "Shanli" kiwifruit). Level three had no resistance to hypoxia stress (or sensitive) ("Hongyang" kiwifruit).

In view of this, the average subordinate function values of the hypoxia stress-resistant kiwifruit seedling were much larger than 0.6 including "Hayward", "Qinmei", "Jinxiang", "Kuoye" and "Huayou". The average subordinate function values of medium-resistance were at the range of 0.3 - 0.6, including "Maohua", "Xixuan", "Jinhua", "Shanli". The average subordinate function value of nonresistance was smaller, which distributed below
0.3 including "Hongyang". Evaluation and the actual root zone hypoxia stress test results were basically the same (Figure 1(a)). Therefore, this method could be used to evaluate the anti-hypoxia abilities of kiwi fruit seedlings.

\section{Discussion}

Oxygen was the final receptor in the process of electron transport and oxidative phosphorylation that conducted on mitochondrial membrane. Oxygen could drive ATP and NAD $(\mathrm{P})^{+}$synthesis in order to maintain the necessary for cell growth reduction capacity, which was the core element of plant's normal life metabolism. Therefore plant's growth and development would be affected 
Table 3. Subordinate function values of growing indicators in $\mathbf{1 0}$ kinds of kiwifruit seedlings under hypoxia stress.

\begin{tabular}{|c|c|c|c|c|c|c|c|c|c|c|c|c|c|c|}
\hline \multirow{2}{*}{ Material } & \multicolumn{11}{|c|}{ Code } & \multirow{2}{*}{$\begin{array}{c}\text { Average } \\
\mathrm{L}\end{array}$} & \multirow{2}{*}{$\begin{array}{c}\text { Sequence } \\
\mathrm{M}\end{array}$} & \multirow{2}{*}{$\begin{array}{c}\text { Grade } \\
\mathrm{N}\end{array}$} \\
\hline & A & B & $\mathrm{C}$ & $\mathrm{D}$ & E & $\mathrm{F}$ & $\mathrm{G}$ & $\mathrm{H}$ & I & $\mathrm{J}$ & $\mathrm{K}$ & & & \\
\hline 1 & 0.15 & 0.26 & 0.09 & 0.00 & 0.74 & 0.27 & 0.41 & 0.04 & 0.50 & 0.38 & 0.44 & $0.30^{\mathrm{f}}$ & 9 & II \\
\hline 2 & 0.60 & 0.72 & 0.58 & 0.18 & 0.00 & 0.35 & 0.00 & 0.39 & 0.75 & 0.52 & 0.17 & $0.39^{\mathrm{e}}$ & 7 & II \\
\hline 3 & 0.58 & 0.48 & 0.00 & 0.09 & 0.38 & 0.00 & 1.00 & 0.00 & 0.00 & 0.00 & 0.15 & $0.24^{\mathrm{f}}$ & 10 & III \\
\hline 4 & 1.00 & 1.00 & 0.73 & 0.52 & 0.58 & 1.00 & 0.40 & 0.93 & 0.54 & 0.70 & 0.34 & $0.70^{\mathrm{cd}}$ & 4 & I \\
\hline 5 & 0.49 & 0.52 & 0.34 & 0.48 & 0.70 & 0.66 & 0.04 & 0.28 & 0.52 & 0.43 & 0.39 & $0.44^{\mathrm{e}}$ & 6 & II \\
\hline 6 & 0.93 & 0.89 & 0.81 & 0.46 & 0.81 & 0.91 & 0.93 & 0.97 & 0.64 & 0.82 & 0.98 & $0.83^{\mathrm{b}}$ & 2 & I \\
\hline 7 & 0.00 & 0.00 & 0.47 & 1.00 & 0.50 & 0.00 & 0.08 & 0.26 & 0.42 & 0.62 & 0.00 & $0.30^{\mathrm{f}}$ & 8 & II \\
\hline 8 & 0.97 & 0.95 & 0.88 & 0.84 & 1.00 & 0.98 & 0.73 & 1.00 & 1.00 & 0.92 & 0.90 & $0.93^{\mathrm{a}}$ & 1 & I \\
\hline 9 & 0.65 & 0.91 & 1.00 & 0.78 & 0.77 & 0.39 & 0.10 & 0.72 & 0.78 & 1.00 & 1.00 & $0.74^{\mathrm{c}}$ & 3 & I \\
\hline 10 & 0.37 & 0.30 & 0.95 & 0.63 & 0.69 & 0.44 & 0.43 & 0.79 & 0.76 & 0.95 & 0.52 & $0.62^{\mathrm{d}}$ & 5 & I \\
\hline
\end{tabular}

A: relative growth rate of leaves length; B: relative growth rate of leaves width; C: dry weight; D: max length of new roots; E: height of plant; F: root activity. G: chlorophyll a/b; H: RMP of leaves; I: MDA content of roots; J: MDA content of leaves; K: total photosynthetic pigment content of leaves; L: average of subordinate function values; M: resistance sequencing; N: resistance grade.

by root zone hypoxia. This study showed that, under root zone hypoxia stress, kiwifruit seedling's growth was inhibited: biosynthesis volume reduced, root activity decreased, absorption function declined, chlorophyll a, chlorophyll b, total chlorophyll and carotenoid content decreased, and the ratio between pigments also changed.

Under hypoxia stress, the whole plant dry weight of the kiwifruit seedling was also inhibited, part of the reason might be that hypoxia stress reduced the leaf pigments content and the photosynthate accumulations were affected. In the present study, dry plant weight reduction varied greatly along with different testing materials. Among them, the inhibition degree of hypoxia stress nonresistance "Hongyang" was bigger, and that of "Hayward", "Qinmei”, "Jinxiang”, "Kuoye” were lighter. Therefore, under root zone hypoxia stress, 10 kinds of kiwi fruit seedlings' biomass were closely related to their tolerance-sensitivity. Research results were consistent with that of Malus, chickpea, Brassica napus L. [26-28].

Plant roots were active absorption and synthesis organs, and their growth status and activity level would directly affect nutritional status and yield of plants. The experimental results showed that, under root zone hypoxia stress, the kiwifruit seedling root activity was inhibited, and the reduction degree was obviously different between species. The relative higher activity of "Hayward", "Qinmei", "Kuoye" kiwifruit seedlings' roots will be able to use sufficient nitrate to support photosynthesis and the growth of the aboveground parts. Thereby, low hypoxia-resistant kiwifruit seedling root had easily lost its activity and absorption function under the influence of hypoxia stress. This was because root respiration was inhabited by hypoxia, which caused decrease in the energy supply.

Under root zone hypoxia stress, MDA content in root and leaf increased significantly, which indicated its cell membrane was significantly damaged. Dramatic increasing of MDA content and RMP were caused by the generation of superoxide anion radical and content of hydrogen peroxide [36]. In addition, the strong hypoxiaresistant kiwifruit seedlings' root and leaf MDA content were lower than that of the weaker. Therefore, "Hayward", "Qinmei", "Kuoye", "Huayou" could effectively eliminate the excessive oxygen free radicals produced by hypoxia stress and reduce the cell membrane damage.

Chloroplast was an important cell organelle in the photosynthesis and light energy absorbed by chlorophyll can be converted into stable chemical energy and drive ATP formation via ATPase in the chloroplasts [37]. However environment factors may alter the chlorophyll content, and induce photosynthetic function changes. Reasonable chlorophyll $\mathrm{a} / \mathrm{b}$ could prevent leaves from producing excess free radicals and light oxidation to pigment molecules [38]. When plants suffered from root zone hypoxia stress, changes of chlorophyll contents could be indicative of plants sensitivity to stress. The results in this study showed that, chlorophyll and carotenoids content in the hypoxia-resistant kiwifruit, such as "Hayward", "Qinmei", were affected relatively lightly, but that of weak-resistant kiwifruit seedlings were affected much greatly, such as "Hongyang". So, to the weak hypoxia-resistant kiwifruit seedlings, as chlorophyll content decreased, net photosynthetic rate decreased significantly, but the hypoxia-resistant kiwifruit 
seedlings chlorophyll degradation was less, and could still maintained a higher photosynthetic rate which would accumulate more photosynthetic products and provide more energy material to prolong the survival time [39]. The reason why chlorophyll content and the pigment ratio decreased, it might be due to the large number of active oxygen accumulation induced by hypoxia stress, and the damaged chlorophyll rate had gone beyond its compensation ability. Moreover, chlorophyll a was not so stable as chlorophyll $b$, under the role of reactive oxygen, the former was more easily decomposed and damaged. This might be the main reason why chlorophyll a/b reduced under root zone hypoxia stress.

The hypoxia-resistant kiwifruit seedlings, "Hayward", "Jinxiang", "Qinmei", belonged to Actinidia deliciosa in this experiment. Some varieties, such as "Huayou" that was the natural hybrids of $A$. delicious $\times A$. chinensis var., lied between the strong and moderate hypoxia-resistant transitional site. While the moderate hypoxia-resistant and nonresistant kiwifruit, such as "Xixuan", "Hongyang" belonged to $A$. chinensis var. Under root zone hypoxia stress, these interspecific differences among kiwifruit seedlings might be because of the genetic diversity. Isozyme genetic analysis showed A. deliciosa kiwifruit was a heterologous six ploidy plant, which had 174 chromosomes. While A. chinensis was a homologous tetraploid plant, which had 116 chromosomes [30]. In evolution, allopolyploid plants retained greater vigor and adaptability and were superior to autopolyploid plants. Therefore, A. deliciosa had more abundant genetic basis than A. chinensis var. This might be the genetics factors that yielded different resistance among different kiwifruits. Furthermore, plants adapted to hypoxia conditions, maybe have other mechanisms to cope with this stress, for example the increase of soluble sugars availability and antioxidant defence ability [40]. The future study could be discussed from these factors above.

\section{REFERENCES}

[1] O. Blokhina, E. Virolainen and K. V. Fagerstedt, "Antioxdants, Oxidative Damage and Oxygen Deprivation Stress: A Review," Annals of Botany, Vol. 91, No. 2, 2003, pp. 179-194. doi:10.1093/aob/mcf118

[2] M. Garnczarska and W. Bednarski, "Effect of a ShortTerm Hypoxic Treatment Followed by Re-Aeration on Free Radicals Level and Antioxidative Enzymes in Lupine Roots," Plant Physiology and Biochemistry, Vol. 42, No. 3, 2004, pp. 233-240. doi:10.1016/j.plaphy.2004.01.005

[3] J. M. Teal and J. W. Kanwisher, "Gas Transport in the Marsh Grass, Spartina Alterniflora," Journal of Experimental Botany, Vol. 17, No. 2, 1966, pp. 355-361. doi:10.1093/jxb/17.2.355

[4] R. D. Delaune, S. R. Pezeshki and J. H. Pardue, "An
Oxidation Reduction Buffer for Evaluating the Physiological Response of Plants to Oxygen Stress," Environmental and Experimental Botany, Vol. 30, No. 2, 1990, pp. 243-247. doi:10.1016/0098-8472(90)90070-K

[5] J. Lorenzen, L. H. Larsen, T. Kjær and N. P. Revsbech, "Biosensor Determination of the Microscale Distribution of Nitrate, Nitrate Assimilation, Nitrification, and Denitrification in a Diatominhabited Freshwater Sediment," Applied and Environmental Microbiology, Vol. 64, No. 9, 1998, pp. 3264-3269.

[6] M. C. Drew, "Plant Injury and Adaptation to Oxygen Deficiency in the Root Environment: A Review," Plant and Soil, Vol. 75, No. 2, 1983, pp. 179-199. doi:10.1007/BF02375564

[7] H. Kato-Noguchi, "Hypoxic Acclimation to Anoxia in Avena Roots," Plant Growth Regulation, Vol. 38, No. 1, 2002, pp. 1-5. doi:10.1023/A:1020944924293

[8] A. Dai, K. E. Trenberth and T. R. Karl, "Global Variations in Droughts and Wet Spells: 1990-1995," Geophysical Research Letters, Vol. 25, 1998, pp. 367-370.

[9] M. Hulme, G. J. Jenkins, X. Lu, J. R. Turnpenny, T. D. Mitchell, R. G. Jones, J. M. Murphy, D. Hassell, P. Boorman, R. McDonald and S. Hills, "Climate Change Scenarios for the United Kingdom: The UKCIP02 Scientific Report. Tyndall Centre for Climate Change Research," University of East Anglia, Norwich, 2002.

[10] M. Leul and W. J. Zhou, "Alleviation of Waterlogging Damage in Winter Rape by Application of Uniconazole Effects on Morphological Characteristics, Hormones and Photosynthesis," Field Crops Research, Vol. 59, No. 2, 1998, pp. 121-127. doi:10.1016/S0378-4290(98)00112-9

[11] E. Dickin and D. Wright, "The Effects of Winter Waterlogging and Summer Drought on the Growth and Yield of Winter Wheat (Triticum aestivum L.)," European Journal of Agronomy, Vol. 28, No. 3, 2008, pp. 234-244. doi:10.1016/j.eja.2007.07.010

[12] M. Chérif, Y. Tirilly and R. R. Bélanger, "Effect of Oxygen Concentration on Plant Growth, Lipid Peroxidation, and Receptivity of Tomato Roots to Pythium under Hydroponic Conditions," European Journal of Plant Pathology, Vol. 103, No. 3, 1997, pp. 255-264. doi:10.1023/A:1008691226213

[13] P. Geigenberger, "Response of Plant Metabolism to too Little Oxygen," Current Opinion in Plant Biology, Vol. 6, No. 3, 2003, pp. 247-256. doi:10.1016/S1369-5266(03)00038-4

[14] T. Matsui and T. Tsuchiya, "Root Aerobic Respiration and Growth Characteristics of Three Typha Species in Response to Hypoxia," Ecological Research, Vol. 21, No. 3, 2006, pp. 470-475. doi:10.1007/s11284-005-0143-9

[15] J. Fan, H. Cai, S. Yang, L. Yan and W. Tan, "Comparison between the Effects of Normoxia and Hypoxia on Antioxidant Enzymes and Glutathione Redox State in ex Vivo Culture of CD $34^{+}$Cells," Comparative Biochemistry and Physiology Part B: Biochemistry and Molecular Biology, Vol. 151, No. 2, 2008, pp. 153-158. doi:10.1016/j.cbpb.2008.06.008

[16] T. Bai, C. Li and F. Ma, "Exogenous Salicylic Acid Alleviates Growth Inhibition and Oxidative Stress Induced by 
Hypoxia Stress in Malus robusta Rehd," Journal of Plant Growth Regulation, Vol. 28, No. 4, 2009, pp. 358-366. doi:10.1007/s00344-009-9104-9

[17] M. C. Drew, "Oxygen Deficiency and Root Metabolism: Injury and Acclimation under Hypoxia and Anoxia," Annual Review of Plant Physiology and Plant Molecular Biology, Vol. 48, 1997, pp. 223-250. doi:10.1146/annurev.arplant.48.1.223

[18] S. Narayanan, D. Ruma, B. Gitika, S. K. Sharma, T. Pauline, M. S. Ram, G. Ilavazhagan, R. C. Sawhney, D. Kumarand and P. K. Banerjee, "Antioxidant Activities of Seabuckthorn (Hippophae rhamnoides) during Hypoxia Induced Oxidative Stress in Glial Cells," Molecular and Cellular Biochemistry, Vol. 278, No. 1-2, 2005, pp. 9-14. doi:10.1007/s11010-005-7636-2

[19] K. Terazawa, Y. Maruyama and Y. Morikawa, "Photosynthetic and Stomatal Responses of Larix Kaempferi Seedlings to Short-Term Waterlogging," Ecological Research, Vol. 7, No. 2, 1992, pp. 193-197. doi:10.1007/BF02348500

[20] S. Ahmed, E. Nawata, M. Hosokawa, Y. Domae and T. Sakuratani, "Alterations in Photosynthesis and Some Antioxidant Enzymatic Activities of Mungbean Subjected to Waterlogging," Plant Science, Vol. 163, No. 1, 2002, pp. 117-123. doi:10.1016/S0168-9452(02)00080-8

[21] P. R. Moog and P. Janiesch, "Root Growth and Morphology of Carex Species as Influenced by Oxygen Deficiency," Functional Ecology, Vol. 4, No. 2, 1990, pp. 201-208. doi: $10.2307 / 2389339$

[22] T. R. Rathore, M. Z. K. Warsi, N. N. Singh and S. K. Vasal, "Production of Maize under Excess Soil Moisture (Waterlogging) Conditions," Proceedings of the 2nd Asian Regional Maize Workshop PACARD, Laos Banos, Phillipines, February 1998, pp. 23-27.

[23] Y. Mano, M. Muraki, T. Komatsu, M. Fujimori, F. Akiyama and T. Takamizo, "Varietal Difference in PreGermination Flooding Tolerance and Waterlogging Tolerance at the Seedling Stage in Maize Inbred Lines," Japanese Journal of Crop Science, Vol. 71, No. 3, 2002, pp. 361-367. doi:10.1626/jcs.71.361

[24] P. H. Zaidi, G. Srinivasan and N. N. Singh, "Increasing Crop-Water Productivity through Genetic Improvement for Tolerance to Water stresses in Maize (Zea mays L.). New Directions for Adiverse Planet," Proceedings the 4th International Crop Scier Congress, Vol. 26, Brisbane, September-October 2004. http://www.cropscience.org.au

[25] B. Tang, S.-Z. Xu, X.-L. Zou, Y.-L. Zheng and F.-Z. Qiu, "Changes of Antioxidative Enzymes and Lipid Peroxidation in Leaves and Roots of Waterlogging-Tolerant and Waterlogging-Sensitive maize Genotypes at Seedling Stage," Agricultural Sciences in China, Vol. 9, No. 5, 2010, pp. 651-661. doi:10.1016/S1671-2927(09)60140-1

[26] T. Bai, R. Yin, C. Li, F. Ma, Z. Yue and H. Shu, "Comparative Analysis of Endogenous Hormones in Leaves and Roots of Two Contrasting Malus Species in Response to Hypoxia Stress," Journal of Plant Growth Regulation, Vol. 30, No. 2, 2011, pp. 119-127. doi:10.1007/s00344-010-9173-9

[27] J. A. Palta, A. Ganjealic, N. C. Turnerb and K. H. M.
Siddiqueb, "Effects of Transient Subsurface Waterlogging on Root Growth, Plant Biomass and Yield of Chickpea," Agricultural Water Management, Vol. 97, No. 10, 2010, pp. 1469-1476. doi:10.1016/j.agwat.2010.05.001

[28] Y. Cheng, M. Gu, Y. Cong, C.-S. Zou, X.-K. Zhang and H.-Z. Wang, "Combining Ability and Genetic Effects of Germination Traits of Brassica napus L. under Waterlogging Stress Condition," Agricultural Sciences in China, Vol. 9, No. 7, 2010, pp. 951-957. doi:10.1016/S1671-2927(09)60176-0

[29] M. L. Dionisio-Sese and S. Tobita, "Antioxidant Responses of Rice Seedlings to Salinity Stress," Plant Science, Vol. 135, No. 1, 1998, pp. 1-9. doi:10.1016/S0168-9452(98)00025-9

[30] H. W. Huang, “Advances in Actinidia Research II," Vol. 12, No. 1, Science Press, Beijing, 2003, pp. 137-137.

[31] D. R. Batish, K. Lavanya, H. P. Singh and R. K. Kohli, "Phenolic Allelochemicals Released by Chenopodium Murale Affect the Growth, Nodulation and Macromolecule Content in Chickpea and Pea," Plant Growth Regulation, Vol. 51, No. 2, 2007, pp. 119-128. doi:10.1007/s10725-006-9153-Z

[32] J. F. G. M. Wintermans and A. Demots, "Spectrophotometric Characteristics of Chlorophyll $\mathrm{a}$ and $\mathrm{b}$ and Their Pheophytins in Ethanol," Biochimica et Biophysica Acta, Vol. 109, No. 2, 1965, pp. 448-453. doi:10.1016/0926-6585(65)90170-6

[33] R. L. Heath and L. Packer, "Photoperoxidation in Isolated Chloroplasts. I. Kinetics and Stoichiometry of Fatty Acid Peroxidation," Archives of Biochemistry and Biophysics, Vol. 125, No. 1, 1968, pp. 189-198. doi:10.1016/0003-9861(68)90654-1

[34] Y. S. Wei, Z. S. Li, L. Shan and C. L. Zhang, "Comprehensive Evaluation on Alfalfa Drought-Resistance Traits by Subordinate Function Values Analysis," Pratacultural Science, Vol. 22, 2005, pp. 33-36.

[35] M. Issarakraisilaa, Q. Mab and D. W. Turner, "Photosynthetic and Growth Responses of Juvenile Chinese Kale (Brassica oleracea var. alboglabra) and Caisin (Brassica Rapa Subsp. Parachinensis) to Waterlogging and Water Deficit," Scientia Horticulturae, Vol. 111, No. 2, 2007, pp. 107-113. doi:10.1016/j.scienta.2006.10.017

[36] C. Y. Li, T. H. Bai, F. W. Ma and M. Y. Han, "Hypoxia Tolerance and Adaptation of Anaerobic Respiration to Hypoxia Stress in Two Malus Species," Scientia Horticulturae, Vol. 124, No. 2, 2010, pp. 274-279. doi:10.1016/j.scienta.2009.12.029

[37] C. F. Zheng, D. Jiang, F. L. Liu, T. B. Dai, Q. Jing and W. X. Cao, "Effects of Salt and Waterlogging Stresses and Their Combination on Leaf Photosynthesis, Chloroplast ATP Synthesis, and Antioxidant Capacity in Wheat," Plant Science, Vol. 176, No. 4, 2009, pp. 575-582. doi:10.1016/j.plantsci.2009.01.015

[38] G. M. Pastori and V. S. Trippi, "Oxidative Stress Induces High Rate of Glutathione Reductase Synthesis in a Drought Resistant Maize Strain," Plant \& Cell Physiology, Vol. 33, No. 7, 1992, pp. 957-961.

[39] C. G. Kuo and B. W. Chen, "Physiological Response of 
Tomato Cultivars to Flooding," Journal of the American Society for Horticultural Science, Vol. 105, No. 5, 1980, pp. 751-755.

[40] R. K. Sairam, D. Kumutha, K. Ezhilmathi, P. S. Desh- mukh and G. C. Srivastava, "Physiology and Biochemistry of Waterlogging Tolerance in Plants," Biologia Plantarum, Vol. 52, No. 3, 2008, pp. 401-412. doi:10.1007/s10535-008-0084-6 